\title{
Large daphniids are keystone species that link fish predation and phytoplankton in trophic cascades
}

\author{
Žiga Ogorelec ${ }^{1, *,+}$, Carsten Wunsch ${ }^{1,+}$, Alessandra Janina Kunzmann", \\ Pelita Octorina ${ }^{1,2}$ and Jana Isanta Navarro ${ }^{1,3}$
}

With 5 figures and 2 tables

\begin{abstract}
Daphniids act as keystone species in lake ecosystems by controlling phytoplankton biomass and experiencing intense fish predation. However, the importance of single daphniid species as trophic links between phytoplankton and fish remains unclear, especially compared with other zooplankton taxa. To disentangle the role of individual zooplankton taxa in the food web of a large lake, we performed an in-situ mesocosm experiment with natural phytoplankton and zooplankton communities in three treatments with native, invasive or no fish predators, respectively. A large daphniid, Daphnia longispina, was the zooplankter most strongly predated by both fish species, and also had the highest top-down effects on phytoplankton. All other zooplankton taxa, including a small daphniid species, had minor roles in terms of both predation by fish and grazing on phytoplankton. We suggest that daphniid species with large body sizes can strongly link higher and lower trophic levels in lake food webs, and thus function as keystone species in trophic cascades from fish to phytoplankton.
\end{abstract}

Keywords: Cladocera; Daphnia; food chain; ecosystem dynamics; oligotrophic lake; pelagic; trophic cascading

\section{Introduction}

Understanding the ecological roles of individual species and their interactions within food webs is essential for the characterisation of ecosystem dynamics. This is particularly true for keystone species, which have a strong influence on ecosystem functioning (Cottee-Jones \& Whittaker 2012). For example, predator-mediated reductions in the abundance of keystone prey species can have indirect effects on lower trophic levels, resulting in trophic cascades (Carpenter et al. 1985; Moyle \& Light 1996; Pagnucco et al. 2016). However, the influence of keystone prey species on food webs may change if the predation pressure they experience shifts, for example, due to the invasion of a new predator.
The development of strong trophic cascading effects depends on multiple factors, and disentangling top-down and bottom-up regulation within food webs may therefore be difficult. In general, bottom-up control is more pronounced at the base of food webs, whereas top-down control is stronger at higher trophic levels (Brett \& Goldman 1997). Therefore, fish have a greater role in regulating zooplankton biomass and abundance than nutrients, but have less influence on phytoplankton (Post \& McQueen 1987; Hansson et al. 2004; Vakkilainen et al. 2004). Multi-level cascades often occur in aquatic ecosystems (Jürgens 1994; Östman et al. 2016), especially when fish predation affects species with key roles in linking different trophic levels and transferring energy through food chains (Hansson et al. 2004).

\section{Authors' addresses:}

${ }^{1}$ Limnological Institute, University of Konstanz, Mainaustraße 252, 78464 Konstanz, Germany

2 Department of Aquaculture, Muhammadiyah University of Sukabumi, R. Syamsudin SH 50, 43113 Sukabumi, Indonesia

${ }^{3}$ Flathead Lake Biological Station, University of Montana, Polson, MT 59860, USA

* Corresponding author: ziga.ogorelec@gmail.com

+ These authors contributed equally to this work and share the first authorship 
Although zooplankton represent a link between primary producers and fish in freshwater ecosystems (Brooks \& Dodson 1965; Hansson et al. 2007), not all zooplankters are keystone species that link trophic levels. Substantial differences in functional traits between species lead to their different effects on phytoplankton (Cyr \& Curtis 1999; Sommer et al. 2003; Barnett et al. 2007), and conceptualising zooplankton as a homogeneous functional group thus masks species-specific roles in within food webs. Hence, studies considering the effects of total zooplankton biomass on phytoplankton have typically found no or only weak top-down effects (McQueen et al. 1989; Mehner et al. 2008). More pronounced cascading effects have been observed for zooplankton of the genus Daphnia (McQueen et al. 1986; McQueen et al. 1989), which are considered as keystone taxa that link primary and tertiary production due to their effective grazing on a broad size spectrum of edible phytoplankton (Lampert 1987). As well as influencing phytoplankton in green food webs, Daphnia can cause complex cascading effects in detritivore-based brown food webs by consuming microorganisms through non-selective grazing (Zöllner et al. 2003).

Body size is among the most important traits influencing both zooplankton filtration rates and therefore top-down control of lower trophic levels (Gianuca et al. 2016). Many Daphnia species are large zooplankters and are therefore keystone grazers with a high capacity to reduce phytoplankton biomass (Vakkilainen et al. 2004). Larger-bodied daphniids can outcompete smaller species due to consuming wider range of phytoplankton, and the growth and reproduction of largerbodied daphniids is greater when phytoplankton densities are low (Gliwicz 1990a; Gliwicz 1990b). Body size also influences fish predation, because most fish are size-selective predators that prefer larger and less evasive prey (Brooks \& Dodson 1965). Daphnia densities can be strongly reduced by specialised planktivorous fish, which typically leads to an increase in phytoplankton biomass (Williams \& Moss 2003).

Although many studies have considered fish effects on zooplankton and consequently on phytoplankton (Helminen \& Sarvala 1997; Bertolo et al. 2000; Williams \& Moss 2003; Vakkilainen et al. 2004), the importance of individual zooplankton species within trophic cascades is still poorly understood, even for potential keystone species such as daphniids. The role of individual zooplankton species in trophic cascades is challenging to investigate within natural ecosystems because species-specific effects are difficult to isolate. Equally, small-scale ex-situ top-down experiments de- signed to compare the feeding impacts of individual species on phytoplankton (Adrian \& Schneider-Olt 1999; Gianuca et al. 2016) lack a natural zooplankton community structure as well as predation by fish. Insitu mesocosm experiments, which allow examination of natural zooplankton communities exposed to natural predation, rarely focus on the effects of single zooplankton species on phytoplankton (Lynch 1979; Bertolo et al. 2000; Hansson et al. 2004). The role of individual zooplankton species in lake food webs thus remains unclear, especially in deeper pelagic and oligotrophic environments.

To investigate the trophic roles of individual zooplankton species, we performed a mesocosm experiment in an offshore area of Upper Lake Constance, central Europe. This area allowed us to represent the pelagic environment using natural phytoplankton and zooplankton communities and the two most abundant pelagic fish species, the native whitefish (Coregonus wartmanni; hereafter, whitefish), and the invasive three-spined stickleback (Gasterosteus aculeatus; hereafter, stickleback). Our aim was to determine which zooplankters function as keystone species that represent strong links between fish predation and phytoplankton biomass, and which zooplankters are susceptible to changes in top-down predation in natural environments. We tested four hypotheses: 1) smaller and more evasive zooplankton species and combined groups of multiple zooplankton species are less susceptible to fish predation than large daphniid species; 2) as specialised planktivores, native whitefish consume more zooplankton than sticklebacks, which are generalist feeders; 3 ) large daphniids cause greater reductions in edible and total phytoplankton biovolumes than other zooplankton taxa; and 4) fish stimulate increases in phytoplankton biovolumes by decreasing large daphniid densities.

\section{Methods}

\section{Study sites}

Lake Constance is a large $\left(536 \mathrm{~km}^{2}\right)$, deep (maximum $251 \mathrm{~m}$ ) pre-Alpine lake situated at the border of Germany, Switzerland and Austria. It consists of two basins, the Lower Lake Constance and the larger Upper Lake Constance, in which our study was performed. Upper Lake Constance experienced several decades of anthropogenic eutrophication during the $20^{\text {th }}$ century with phosphorus concentrations peaking in 1979, but has since returned to an oligotrophic state due to restoration efforts (IGKB 2013; Schotzko 2018). The most abundant zooplankton taxa in Upper Lake Constance are cyclopoid copepods, the calanoid copepod Eudiaptomus gracilis, and the cladocerans Diaphanosoma brachyurum, Bosmina spp., Daphnia longispina 
(formerly known as D. hyalina), Daphnia galeata, Leptodora kindtii and Bythotrephes longimanus (Straile \& Geller 1998). Recently, a small daphniid species, Daphnia cucullata, has been recorded at high densities (IGKB 2018, Isanta Navarro et al. 2019). The fish fauna comprises approx. 30 species, of which three are common in the pelagic zone: the native lake char (Salvelinus umbla), the whitefish and the stickleback. The latter is an invasive, non-native species that has been occurring at high densities in the pelagic zone of Upper Lake Constance since 2012-2013 (Rösch et al. 2018; Eckmann \& Engesser 2019), and in 2014 represented $96 \%$ of the total abundance and $28 \%$ of the biomass of pelagic fish (Alexander \& Vonlanthen 2016).

\section{Experimental design}

The experiment was conducted in the Upper Guell bay of Upper Lake Constance between 27 June and 25 July 2019. It comprised 12 plastic cylindrical mesocosms made of transparent polyethylene, each with a $15-\mathrm{m}$ depth, a $96-\mathrm{cm}$ diameter and a $10 \mathrm{~m}^{3}$ volume. Mesocosms were heat-sealed at the base and open to the atmosphere above the water surface. Mesocosms were attached to pontoons, freely hanging in open water, with their bases approx. $2 \mathrm{~m}$ above the sediment. Each pontoon accommodated four mesocosms in a row at $25-\mathrm{cm}$ intervals and in an east-west direction to prevent shading by adjacent mesocosms. Each mesocosm was covered with a transparent acrylic glass plate, to protect it from bird excrement and other external disturbances.

On June 19, the mesocosms were filled with filtered $(<300 \mu \mathrm{m})$ lake water and then inoculated with lake zooplankton. Zooplankton were sampled using vertical net tows $(300 \mu \mathrm{m})$ from a depth of $15 \mathrm{~m}$ to the surface, filtering the same volume of water as in the 12 mesocosms, to ensure inoculation of zooplankton at natural densities at these depths. Samples were filtered through a $630-\mu \mathrm{m}$ sieve to remove predatory zooplankton such as L. kindtii and B. longimanus as well as fish larvae; this process also removed the largest adult daphniids and copepods. The sampled zooplankton volume was then divided into 12 equal parts and one part added to each mesocosm. Zooplankton were then left to acclimatise within the mesocosms for eight days, allowing conditions to stabilise and zooplankton to develop to adult sizes (Schwartz 1984; Peterson 2001). The experiment lasted four weeks, to provide enough time for phytoplankton and zooplankton reproduction, community development and response to experimental conditions (Riebesell et al. 2011). To enable characterisation of well-pronounced top-down effects, the experimental period coincided with the lake's phytoplankton spring peak, which occurred unusually late in the study year i.e. around 1 July (unpublished data).

Treatments were randomly assigned to mesocosms, ensuring that each pontoon had at least one replicate of each treatment and that the treatments were placed in different orders within the pontoons. After the acclimatisation period ended (i.e. day 0, 27 June), the first samples were collected from all mesocosms (see below), and predatory zooplankton and fish were then added to treatments. Due to the patchy distribution of larger predatory zooplankton species and their potentially important roles in pelagic food webs, 200 L. kindtii and 40 B. longimanus were counted and added separately to each mesocosm, representing $1 / 4$ and $1 / 5$ of their typical maximum Lake Constance densities, respectively. These densities were limited by unusually low numbers of these two species in the lake dur- ing the study period. A treatment containing only zooplankton (including predatory taxa) acted as the control.

Two fish treatments received either four sticklebacks (mean $\pm \mathrm{SD}, 0.31 \pm 0.048 \mathrm{~g}$ ) or four whitefish $(0.32 \pm 0.093 \mathrm{~g}$ ). The body length of whitefish was generally greater than that of sticklebacks with the same biomass, although exact lengths were not measured. Total fish densities in mesocosms were $1.71 \pm 0.096 \mathrm{~g} \mathrm{~m}^{-2} \mathrm{SD}$ for sticklebacks and $1.77 \pm 0.094 \mathrm{~g} \mathrm{~m}^{-2}$ SD for whitefish, representing natural densities in Lake Constance. Because fish densities in the lake are difficult to estimate precisely, annual fishery yields of adult whitefish were used as a reference, with 2007-2016 yields corresponding to $0.58 \mathrm{~g} \mathrm{~m}^{-2}$ (Kugler \& Friedl 2018). Because adult whitefish dominate pelagic fish biomass (Alexander \& Vonlanthen 2016) and because they are usually harvested soon after reaching their adult size (Eckmann \& Rösch 1998), densities 2-3 times higher than annual whitefish yields might adequately represent actual densities in the lake.

\section{Sampling and sample processing}

Starting on day 0 , abiotic parameters were measured and both phytoplankton and zooplankton samples were taken from mesocosms. Sampling frequency was different for each parameter. Twice a week, dissolved oxygen concentrations, $\mathrm{pH}$ and temperature were measured in each mesocosm and in the lake with a multiparameter probe (CTD-90 M; Sea\&Sun Technology), and chlorophyll concentrations were measured with a fluorescence probe (bbe Moldaenke, TS 17-09). These abiotic measurements were taken by lowering probes from the surface to a depth of $12 \mathrm{~m}$, prior to disturbance of the water column during biotic sample collection. Zooplankton were sampled using vertical net hauls $(16.5-\mathrm{cm}$ opening, $100-\mathrm{cm}$ length and $100-\mu \mathrm{m}$ mesh) from a depth of $12 \mathrm{~m}$ to the mesocosm surface, on days 0 , 14, 21 and 28. Phytoplankton were sampled on days 0,14 and 28 by performing a vertical tow with an integrated water sampler across the same depth range, which collected $2 \mathrm{~L}$ of water, from which $100-\mathrm{mL}$ subsamples were taken for analysis.

Collected zooplankton samples were preserved at $-20^{\circ} \mathrm{C}$ until processing. After thawing, samples were divided into aliquots of $\geq 300$ zooplankters, identified to the lowest taxonomic resolution possible (order to species), counted, and values used to back-calculate densities of each taxon. Although hybrids of the three Daphnia species probably occurred in our samples (Isanta Navarro et al. 2019), we designated each as only one of three species based on its morphological features. All copepod life stages were included except nauplii, due to their inconsistent sampling by a $100-\mu \mathrm{m}$ mesh and identification difficulties. The five most abundant taxa were used for further analyses: Bosmina spp. (3.6\%), Cyclopoida (20.5\%), E. gracilis $(10.1 \%)$, D. cucullata (44.9\%) and D. longispina (20.8\%). In addition, D. longispina and D. cucullata were combined as a total daphniid fraction. All other zooplankton taxa (including D. galeata) represented $<0.2 \%$ of total zooplankton abundance and were therefore excluded from further analysis.

Phytoplankton samples were fixed in Lugol's acid solution + sodium acetate, identified to genus level using an inverted light microscope and counted following Utermöhl (1958). Biovolumes were calculated using taxon-specific body volumes established for Lake Constance (Pauli 1989; Kümmerlin \& Bürgi 1989; Müller et al. 1991). Phytoplankton species were divided into two groups according to their edibility to large daphniids. Unicellular taxa $<40 \mu \mathrm{m}$ in cell length were classified as edible, 
whereas those $>40 \mu \mathrm{m}$ in cell length, colony-forming and mucilaginous species were classified as inedible (Lampert 1987); cell lengths were based on Rimet \& Druart (2018).

\section{Data analysis}

Shapiro-Wilk tests confirmed that all zooplankton and phytoplankton data had normal distributions. Initial (day 0) total zooplankton densities were compared with a one-way ANOVA, to ensure comparability among treatments. To compare densities of different zooplankton species among treatments (hypothesis 1) including identification of differences between the whitefish and stickleback treatments (hypothesis 2), we performed a twoway repeated-measures (RM) ANOVA with treatment (control, whitefish, stickleback) as the between-subjects factor and day $(0,14,21,28)$ as the within-subjects factor. Mauchly's tests were used to test the RM ANOVA assumption of sphericity, with deviations from sphericity addressed using GreenhouseGeisser corrections. Pairwise t-tests with Bonferroni corrections were used to identify differences between treatments on each day. Linear regression models (LM) were used to identify relationships between the densities of zooplankton taxa (as predictor variables) and total, edible and inedible fractions of phytoplankton biovolumes (as dependent variables; hypothesis 3 ). To test hypothesis 4, a second RM ANOVA and pairwise tests (as described above) were done to compare phytoplankton biovolumes in each treatment. All analyses were done in the statistical software R (R Core Development Team 2018), us- ing the package afex (Singmann et al. 2020) to perform RM ANOVAs and Mauchly's tests, the basic R function $\operatorname{lm}()$ to run LM, and the package ggplot2 (Wickham 2016) to plot graphics.

\section{Results}

Abiotic conditions were stable during the experiment: dissolved oxygen ranged from $10-12 \mathrm{mg} \mathrm{L}^{-1}$ at the surface to $12-15 \mathrm{mg} \mathrm{L}^{-1}$ at a depth of $12 \mathrm{~m}, \mathrm{pH}$ varied between $8.5-9.5$ at all depths, and temperatures ranged from $22-25^{\circ} \mathrm{C}$ at the surface to $10-12{ }^{\circ} \mathrm{C}$ at $12 \mathrm{~m}$.

Zooplankton densities were comparable in all treatments at the start of the experiment (i.e. on day 0; oneway ANOVA $\mathrm{F}_{2,6}=0.03, p=0.969$ ). Total zooplankton and total daphniid densities differed among treatments but not days, and no interactions were identified between day and treatment (RM ANOVA, Table 1). Both total zooplankton densities (pairwise t-test, $p=0.012$ ) and total daphniid densities $(p=0.004)$ were higher in the control than in the whitefish treatment but not the stickleback treatment $(p>0.05)$. The large daphniid D. longispina was the only zooplankton taxon whose densities responded to fish, including a significant

Table 1. Results of two-way repeated-measures ANOVAs describing differences in zooplankton densities and total phytoplankton biovolumes among treatments, days and their interaction. Significant results $(p<0.05)$ are indicated in bold.

\begin{tabular}{|c|c|c|c|c|}
\hline Group & Effect & df & $\mathbf{F}$ & p \\
\hline \multirow{3}{*}{ Bosmina spp. } & Treatment & 2 & 1.19 & 0.367 \\
\hline & Day & 3 & 5.36 & 0.025 \\
\hline & Treatment $\times$ day & 6 & 0.96 & 0.462 \\
\hline \multirow{3}{*}{ Cyclopoida } & Treatment & 2 & 0.82 & 0.484 \\
\hline & Day & 3 & 11.78 & $<0.001$ \\
\hline & Treatment $\times$ day & 6 & 1.25 & 0.336 \\
\hline \multirow{3}{*}{ Daphnia cucullata } & Treatment & 2 & 1.64 & 0.26 \\
\hline & Day & 3 & 5.17 & 0.036 \\
\hline & Treatment $\times$ day & 6 & 1.21 & 0.353 \\
\hline \multirow{3}{*}{ Daphnia longispina } & Treatment & 2 & 28.60 & $<0.001$ \\
\hline & Day & 3 & 2.46 & 0.133 \\
\hline & Treatment $\times$ day & 6 & 3.84 & $\mathbf{0 . 0 3 7}$ \\
\hline \multirow{3}{*}{ Eudiaptomus gracilis } & Treatment & 2 & 2.48 & 0.164 \\
\hline & Day & 3 & 9.70 & 0.03 \\
\hline & Treatment $\times$ day & 6 & 2.06 & 0.152 \\
\hline \multirow{3}{*}{ Total daphniids } & Treatment & 2 & 11.39 & 0.006 \\
\hline & Day & 3 & 1.28 & 0.306 \\
\hline & Treatment $\times$ day & 6 & 1.96 & 0.184 \\
\hline \multirow{3}{*}{ Total zooplankton } & Treatment & 2 & 6.69 & 0.024 \\
\hline & Day & 3 & 0.22 & 0.751 \\
\hline & Treatment $\times$ day & 6 & 1.77 & 0.212 \\
\hline \multirow{3}{*}{ Total phytoplankton } & Treatment & 2 & 11.28 & 0.005 \\
\hline & Day & 2 & 147.73 & $<0.001$ \\
\hline & Treatment $\times$ day & 4 & 8.546 & 0.006 \\
\hline
\end{tabular}



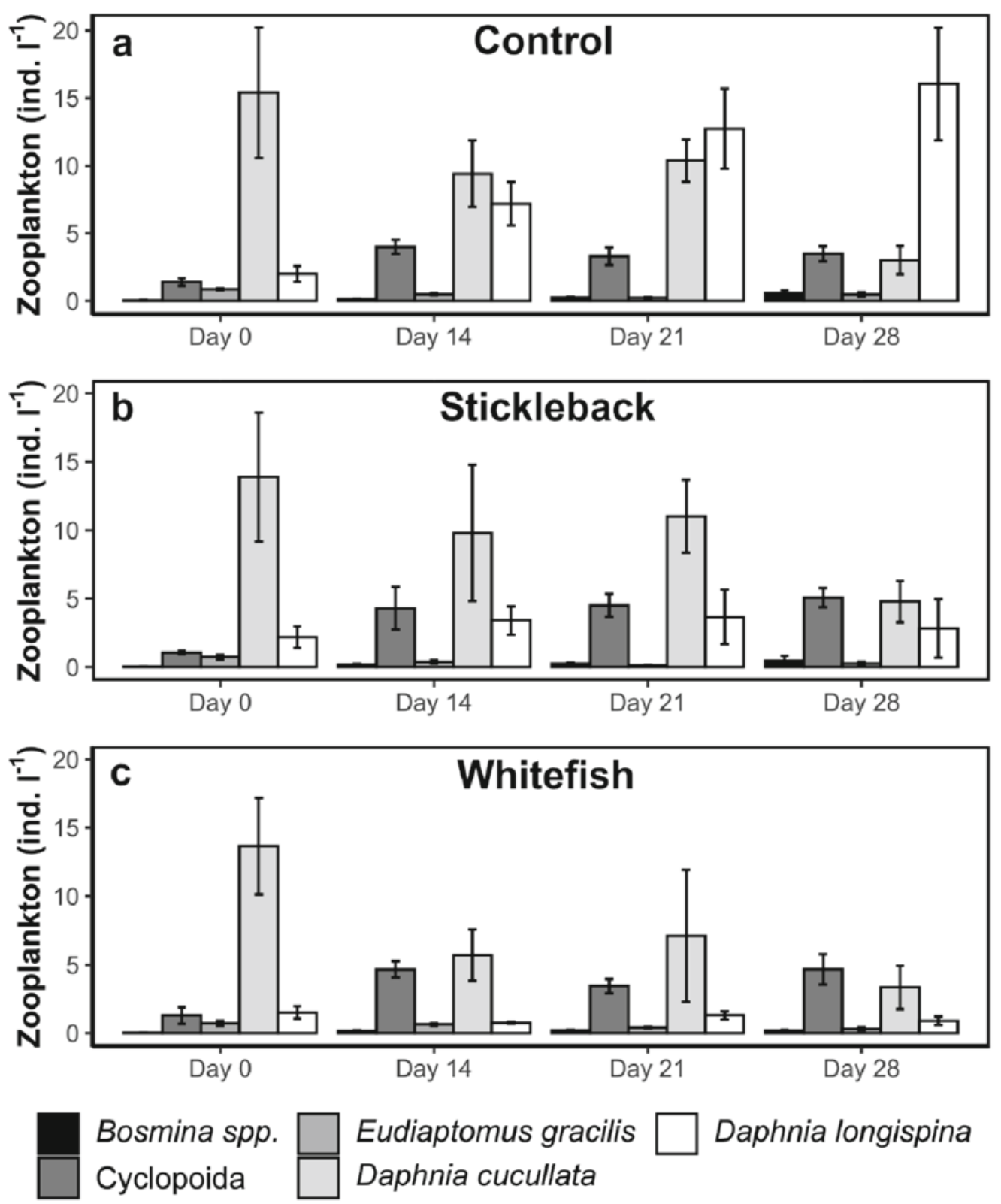

Fig. 1. Mean ( $\pm 1 \mathrm{SD})$ zooplankton taxa densities (individuals [ind.] $\left.1^{-1}\right)$ in control (a), stickleback (b) and whitefish (c) treatments on each sampling day.

treatment effect and a significant treatment-day interaction (Table 1, Fig. 1): while D. longispina densities were comparable on all days in both fish treatments, densities increased over time in the control treatment (Table 1, Fig. 2). Daphnia longispina densities were lower in the whitefish treatment compared to the control treatment on days 14 (pairwise t-test, $p=0.005$ ), $21(p=0.012)$ and $28(p=0.009)$. Densities of this taxon were also higher in the stickleback treatment compared to the control on days $21(p=0.038)$ and $28(p=0.013)$. Densities of all other zooplankton taxa changed over time but did not differ among treatments, and no interactions were identified between treatment and time (Table 1, Fig. 1). Bosmina spp. (pairwise ttest, $p=0.013)$ and Cyclopoida $(p<0.001)$ densities increased whereas E. gracilis and D. cucullata densities decreased $(p<0.001)$ between day 0 and day 28 .

Total phytoplankton biovolumes were negatively related to D. longispina densities on both day 14 (LM; $p=0.049)$ and day $28(p=0.01)$, and also to total daphniid densities on day 28 ( $p=0.03$; Table 2$)$. Increasing D. longispina densities were related to a decline 


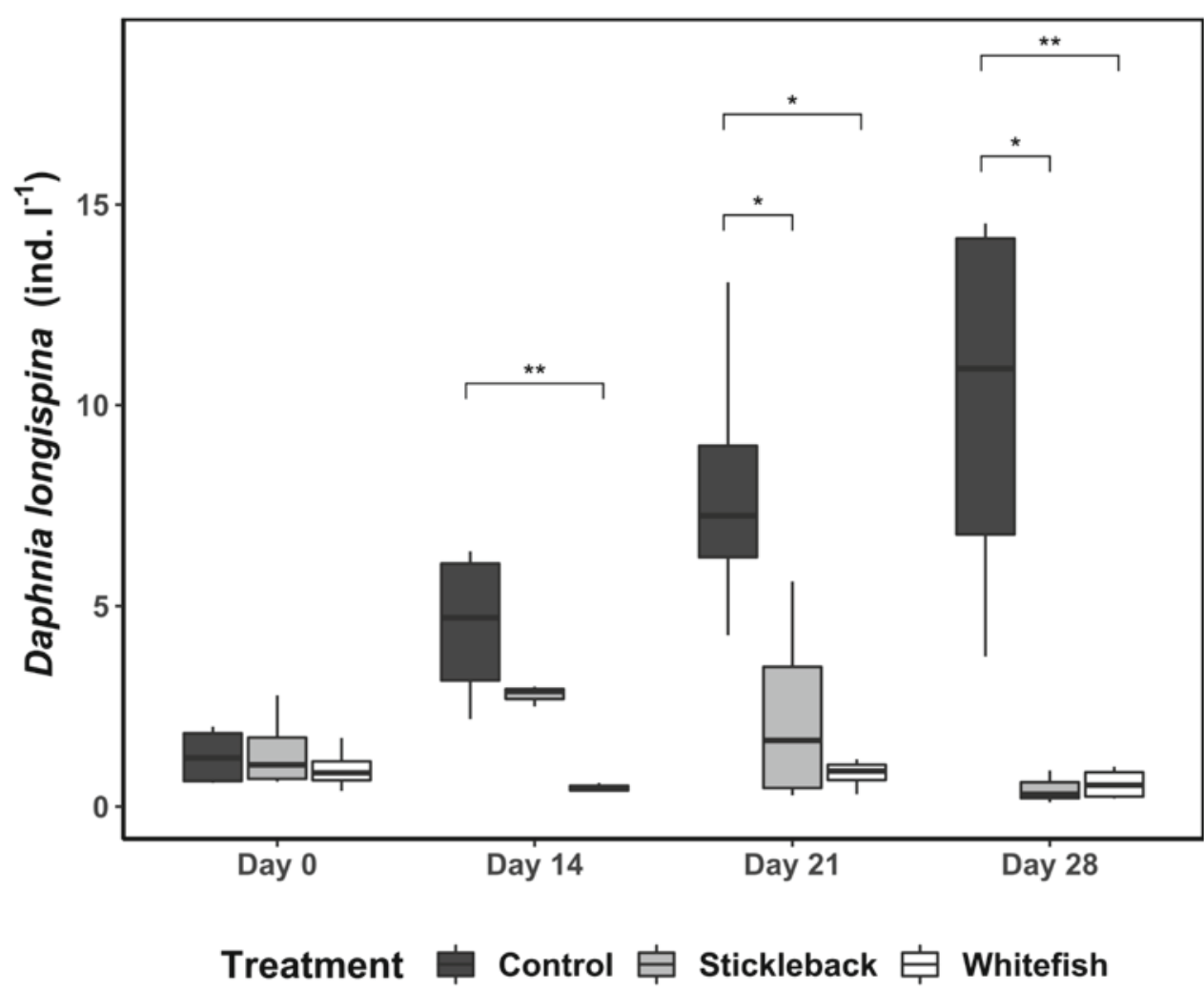

Fig. 2. Daphnia longispina densities (individuals [ind.] $1^{-1}$ ) in each treatment on each sampling day. The results of the pairwise ttests comparing treatments are indicated by brackets and asterisks $(* p<0.05, * * p<0.01)$.

Table 2. Linear model results describing relationships between total phytoplankton biovolumes and densities of different zooplankton taxa and groups. Significant results $(p<0.05)$ are indicated in bold.

\begin{tabular}{|l|c|c|c|c|}
\hline \multirow{2}{*}{ Zooplankton taxon/group } & \multicolumn{2}{|c|}{ Day $\mathbf{1 4}$} & \multicolumn{2}{c|}{ Day $\mathbf{2 8}$} \\
\cline { 2 - 5 } & $\mathbf{R}^{\mathbf{2}}$ & $\boldsymbol{p}$ & $\mathbf{R}^{\mathbf{2}}$ & $\boldsymbol{p}$ \\
\hline Bosmina spp. & 0.04 & 0.54 & 0.06 & 0.45 \\
\hline Cyclopoida & 0.00 & 0.89 & 0.24 & 0.11 \\
\hline Daphnia cucullata & 0.12 & 0.27 & 0.00 & 0.98 \\
\hline Daphnia longispina & $\mathbf{0 . 3 3}$ & $\mathbf{0 . 0 4 9}$ & $\mathbf{0 . 5 1}$ & $\mathbf{0 . 0 1}$ \\
\hline Eudiaptomus gracilis & 0.20 & 0.14 & 0.18 & 0.17 \\
\hline Total daphniids & 0.14 & 0.23 & $\mathbf{0 . 3 9}$ & $\mathbf{0 . 0 3}$ \\
\hline Total zooplankton & 0.12 & 0.28 & 0.28 & 0.07 \\
\hline
\end{tabular}

in edible phytoplankton biovolumes on day 14 (LM, $\mathrm{R}^{2}=0.41, p=0.025$; Fig. 3a) and day $28\left(\mathrm{R}^{2}=0.56\right.$, $p=0.005$; Fig. $3 \mathrm{~b}$ ), whereas biovolumes of the inedible fraction did not respond to D. longispina densities (Fig. 3c-d). Phytoplankton biovolumes were not related to densities of total zooplankton $(p=0.07)$ or of any other individual taxon ( $p>0.1$; Table 2$)$.

Phytoplankton biovolumes differed between days and treatments and a significant interaction was observed between treatment and date (Table 1). In all treatments, total phytoplankton biovolumes were higher on day 14 compared to day 0 (pairwise t-test, $p<0.001)$ then declined between days 14 and 28 $(p<0.001)$. Compared to the control, biovolumes were higher in the whitefish treatment on days 14 (pairwise t-test, $p=0.001)$ and $28(p<0.001)$ and in the stickleback treatment on day 28 ( $p<0.001$; Fig. 4). Biovolumes were higher in the whitefish treatment compared to the stickleback treatment on day $14(p=0.002$; Fig. 4). 

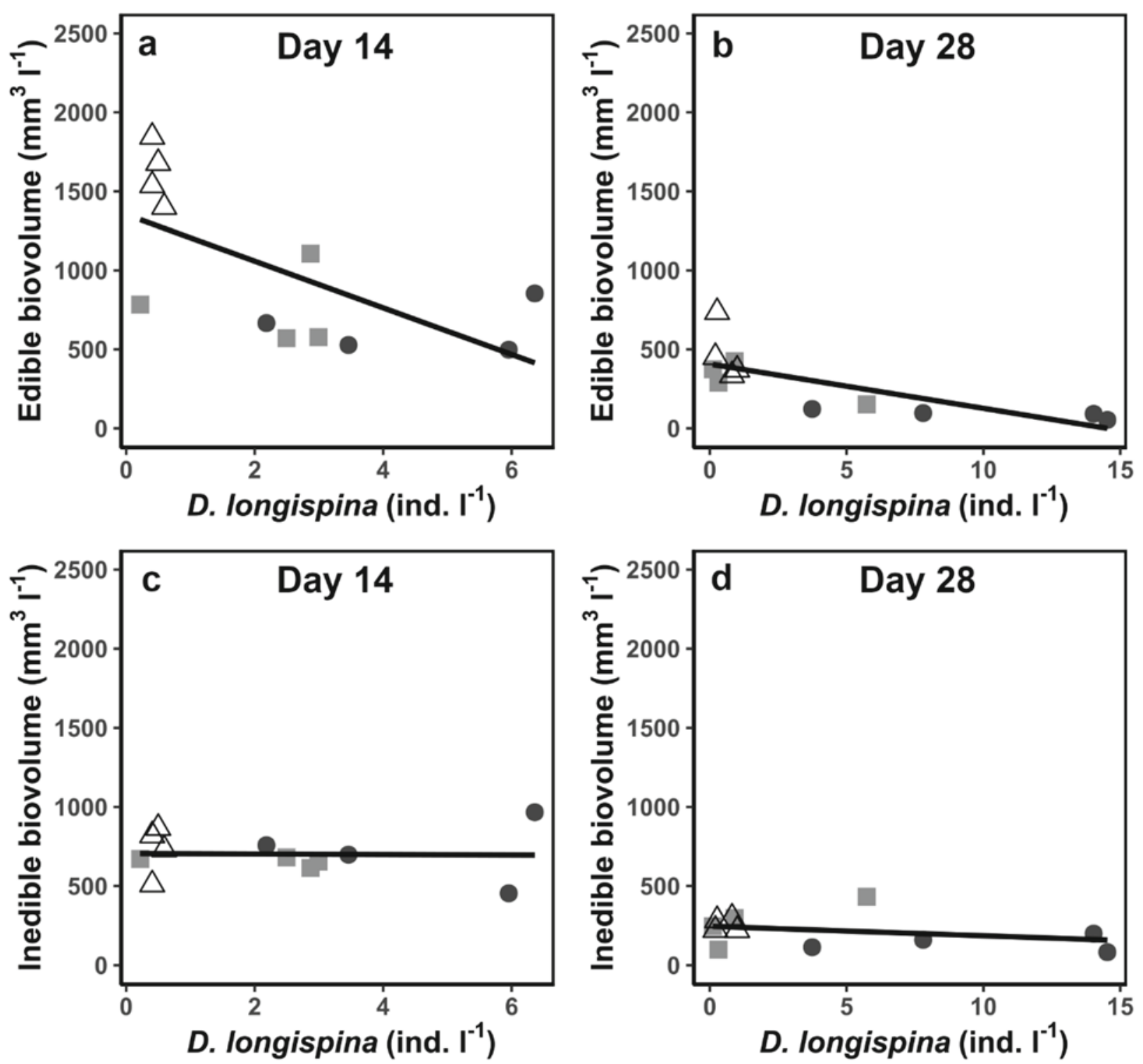

\section{Treatment $\bullet$ Control}

\section{Stickleback $\triangle$ Whitefish}

Fig. 3. Linear model $\left(\mathrm{y}=\mathrm{b}^{*} \mathrm{x}\right)$ showing the relationship between Daphnia longispina densities (individuals [ind.] $\left.1^{-1}\right)$ and biovolumes $\left(\mathrm{mm}^{3} \mathrm{l}^{-1}\right)$ of edible $(<40 \mu \mathrm{m})$ and inedible $(>40 \mu \mathrm{m})$ phytoplankton on day $14(\mathbf{a}, \mathbf{c})$ and day 28 (b, d).

\section{Discussion}

Zooplankton of the genus Daphnia are typically described as keystone grazers that link primary production and higher trophic levels in lake ecosystems, but the roles of single daphniid species remain poorly known. Supporting our first hypothesis, densities of the largest-sized daphniid studied, D. longispina, decreased in response to fish predation. In contrast, densities of other zooplankters, including the small daphniid D. cucullata, did not decline. These findings demonstrate that considering the genus Daphnia as a keystone taxon is a generalisation that overlooks sizemediated differences between species. Whitefish and sticklebacks had comparable effects on zooplankton, which refutes our second hypothesis, that whitefish - as specialised planktivores - have a greater impact on zooplankton communities. Supporting our third hypothesis, phytoplankton biovolumes decreased primarily in response to D. longispina densities, likely their large body size enables filtration of a wider spectrum of phytoplankton taxa and also growth at lower 

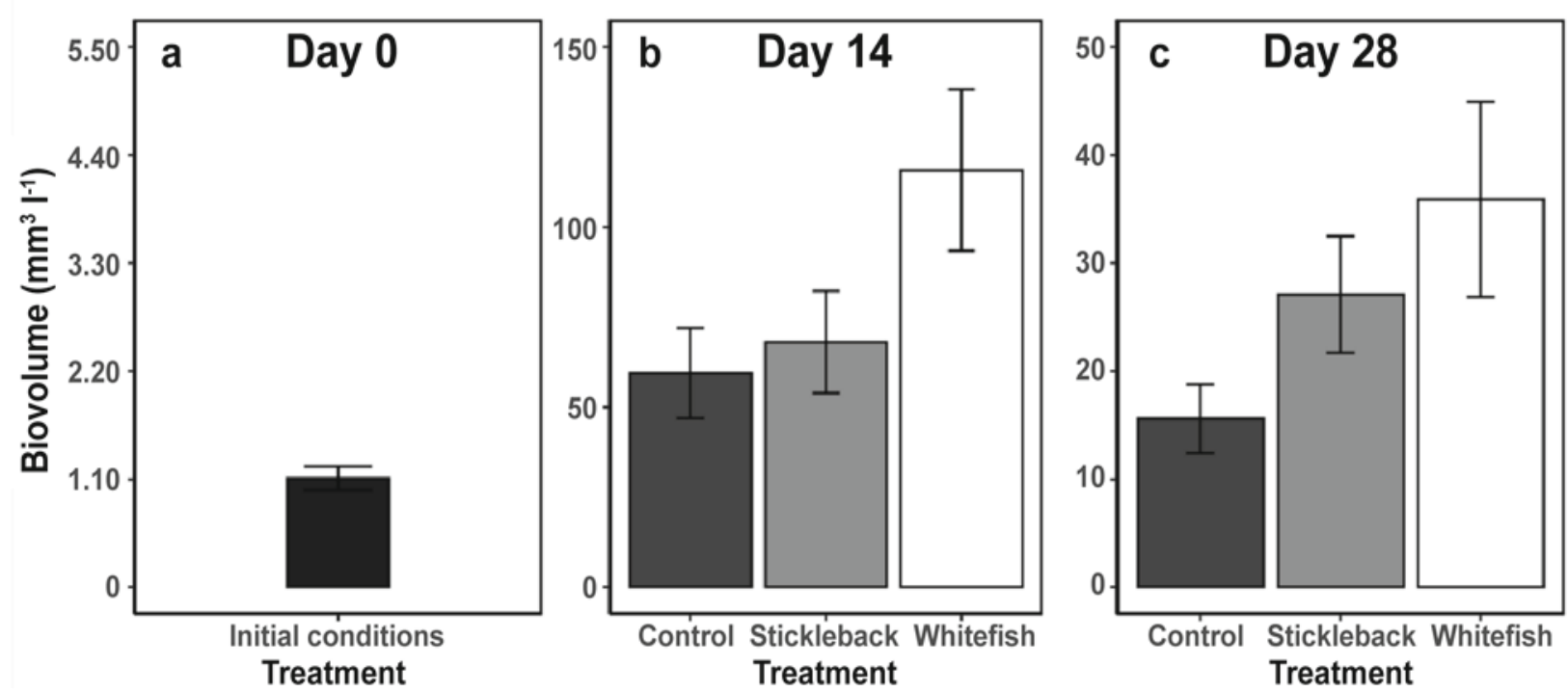

Fig. 4. Mean $\pm 1 \mathrm{SD}$ phytoplankton biovolumes $\left(\mathrm{mm}^{3} \mathrm{l}^{-1}\right)$ in control and fish treatments on sampling days 0 (a), 14 (b) and 28 (c). Identical phytoplankton biovolumes at day 0 are joined in one bar as initial conditions (a).

phytoplankton densities (Gliwicz 1990b). Therefore, evidence of cascading effects was seen as higher phytoplankton biovolumes in fish treatments, caused by fish-mediated decreases in the densities of large daphniids (Fig. 5), supporting our fourth hypothesis. Both fish treatments were linked to comparable increases in phytoplankton densities, which our results suggest were mediated by fish predation on zooplankton, in particular D. longispina. We thus suggest that D. longispina regulates trophic cascades by mediating top down effects in pelagic food webs including fish with both specialist and generalist feeding modes.

\section{Fish predation on zooplankton}

Compared to the initial lake conditions, D. longispina densities increased only in the fishless control treatments, reflecting release from vertebrate predation. Densities of other zooplankton taxa changed over time but not between treatments, suggesting that changes were not predation mediated. The increases in Bosmina spp. and cyclopoid copepods might be seasonal, because comparable increases were observed in the lake during the study. In addition, cyclopoid copepod densities might still have been increasing following inoculation, since their densities were lower on day 0 than on any other date. The drivers of temporal decreases in D. cucullata and E.gracilis are unclear but might reflect specific conditions within the closed mesocosm environment. Although densities of microcrustaceans other than large daphniids can be reduced when fish predation is high (Post \& McQueen 1987; Bertolo et al. 2000), we did not observe such reductions, probably because fish densities were low, as is natural in oligotrophic Lake Constance. Mehner et al. (2008) also found no negative relationship between the biomass of planktivorous coregonid fish and zooplankton species other than Daphnia in an oligotrophic lake.

Various factors contribute to reduced fish predation on zooplankton other than large daphniids. The contrasting movement pattern of cyclopoid and calanoid copepods makes them harder to capture compared to cladocerans such as Daphnia (Visser 2007; Peterka \& Matěna 2011). Furthermore, due to their small size, taxa such as the genus Bosmina are less conspicuous and therefore less predated than larger zooplankters (Brooks \& Dodson 1965). Although fish predate small and evasive zooplankton, densities of some zooplankters can increase at low fish densities due to the removal of their competitors by selective fish predation on larger and less evasive species (Brooks \& Dodson 1965; Christoffersen et al. 1993). Comparable densities of the small daphniid D. cucullata in control and fish treatments may reflect its small size and also its morphology: it is slimmer and therefore less conspicuous than D. longispina of the same body length (Gliwicz 2001). The reactive distance of roach for detecting $D$. longispina is double that for D. cucullata of the same body length, resulting in a near-tenfold larger reactive field volume and thus higher fish predation on D. longispina (Gliwicz 2001). The dominance of small or large-sized zooplankton communities can thus 


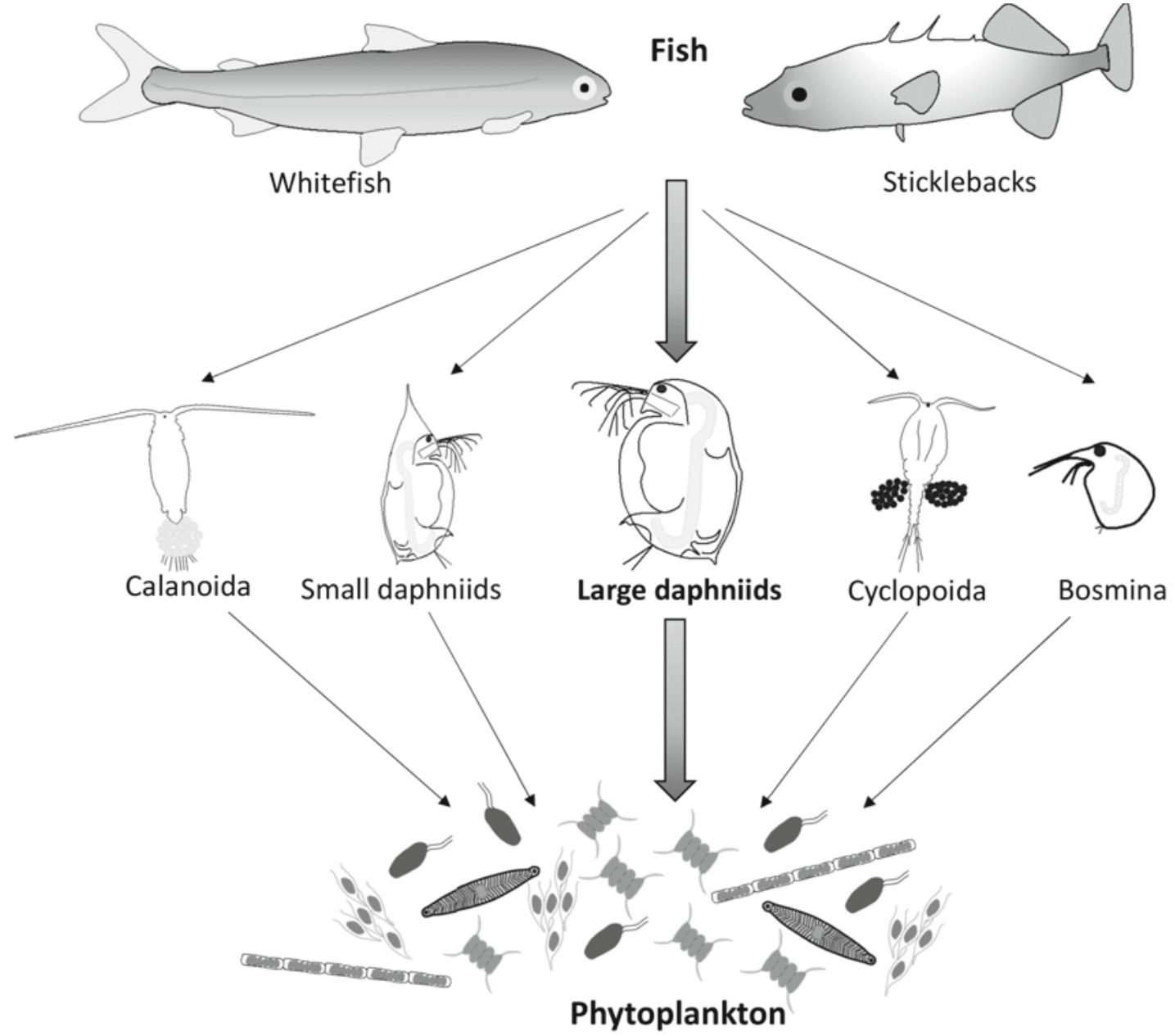

Fig. 5. A conceptual model of trophic cascading from fish (represented by a stickleback and a whitefish) to primary producers (phytoplankton) within a pelagic ecosystem. Thick arrows represent reductions in densities at lower trophic levels. Of all zooplankton taxa, only densities of the large daphniids were reduced by fish predation and thus caused declines in phytoplankton biovolumes, indicating their role as keystone species.

largely reflect predation pressure in lakes (Jeppesen et al. 1997; Iglesias et al. 2017; Ersoy et al. 2017), as indicated in our study by the dominance of $D$. cucullata and cyclopoid copepods in fish treatments and D. longispina in non-fish treatments.

The natural zooplankton community represented in our experiments included two large invertebrate predators, B. longimanus and L. kindtii. Although fish probably influenced their densities, we suggest that invertebrate predators did not cause pronounced differences in prey zooplankton composition between treatments. Invertebrate predation on zooplankton is typically much lower compared to vertebrate (fish) predation (Gliwicz \& Pijanowska 1989; Šorf et al. 2014). In addition, due to their low densities, larger invertebrate predators were rarely observed in our zooplankton samples, and densities of smaller inverte- brate predators (i.e. cyclopoid copepods) did not differ between treatments.

\section{Cascading effects of fish species}

Whitefish did not cause greater reductions in any zooplankton species compared to sticklebacks. However, cascading effects on phytoplankton via consumption of zooplankton (especially D. longispina) were initially more pronounced for whitefish than sticklebacks, as indicated by faster increases in phytoplankton biovolumes (i.e. by day 14). Whitefish are specialised zooplankton feeders with adaptations to pelagic environments whereas sticklebacks are generalist feeders (Morrow 1980; Becker \& Eckmann 1992; Kottelat \& Freyhof 2007), which probably enabled higher whitefish consumption of phytoplankton grazers. Al- 
though differences in zooplankton densities between fish treatments were not significant, moderately lower densities in the whitefish treatment might have been enough to cause significant differences in phytoplankton biovolume. Over time, differences in zooplankton densities and phytoplankton biovolumes between whitefish and sticklebacks became less pronounced, and within 28 days, sticklebacks and whitefish triggered similar trophic cascades. Other mesocosm experiments have indicated greater species-specific differences between fish, with specialised planktivores affecting zooplankton and consequently phytoplankton communities more strongly than facultative planktivorous fish, at least in shallow $(<1 \mathrm{~m})$ eutrophic littoral waters (Williams \& Moss 2003; Des Roches et al. 2013). However, we are not aware of any previous studies with similarly low fish densities and/or sufficiently deep mesocosms to develop a thermocline and thus to represent cascading in pelagic and oligotrophic environments; these factors may explain the contrasting patterns observed in our study.

\section{The effects of large daphniids on phytoplankton biomass}

Many studies indicate that the genus Daphnia causes greater reductions in edible phytoplankton biovolumes than other zooplankton taxa (McQueen \& Post 1988; Adrian \& Schneider-Olt 1999; Mehner et al. 2008). In particular, McQueen et al. $(1986 ; 1989)$ studied how body size influences the effects of Daphnia on phytoplankton biomass and linked large-sized daphniids to reduced biomass in mesoeutrophic and eutrophic environments. Our results build on such research by comparing the effects of different-sized daphniid species, and suggest that larger daphniids such as D. longispina are the main zooplankters that reduce phytoplankton biovolumes in natural lake communities.

Although other zooplankton species, such as copepods, can have complementary effects to daphniids by grazing on different-sized phytoplankton species, thus contributing to greater overall reductions in biomass (Sommer et al. 2001; Sommer et al. 2003), they did not alter phytoplankton biovolumes at the natural densities represented in our communities. Total zooplankton densities had no significant effect on phytoplankton biovolume, due to the pronounced declines caused by D. longispina being offset by the limited effects of other, smaller taxa. Equally, the linear relationship between densities of the genus Daphnia and phytoplankton biovolumes on day 28 reflected only the pronounced effect of $D$. longispina, whereas $D$. cucullata had no effect on biovolumes. These results in- dicate that previous research may have overstated the importance of small Daphnia species, if genus-level responses were caused solely by larger, co-occurring congeners. Larger D. longispina also have higher potential than D. cucullata to increase their population densities due to higher birth and biomass production rates (Vijverberg \& Richter 1982). This greater fecundity might have contributed to increasing $D$. longispina dominance in our fishless mesocosms, where increasing densities enabled greater control of phytoplankton.

\section{Cascading links from fish to phytoplankton}

Our results indicate that $D$. longispina was a keystone species that linked both planktivorous and generalist fish predators to phytoplankton communities (Fig. 5). No other zooplankton or daphniid taxa or groups were so greatly predated by fish or showed such strong phytoplankton control, and multi-taxon groups therefore formed much weaker cascading links between fish and primary producers. Although smaller zooplankton species can also contribute to trophic cascades from fish to phytoplankton if large cladocerans are absent (Christoffersen et al. 1993; Helminen \& Sarvala 1997), most studies indicate that the genus Daphnia - if present - is the taxon most negatively affected by fish predation, and has also the strongest effects on phytoplankton densities (Post \& McQueen 1987; Mehner et al. 2008). However, variability in the roles of different Daphnia species in trophic cascades remains poorly studied.

Although fish can also have a positive effect on phytoplankton growth by remineralising nutrients, this effect is mostly limited to non-edible phytoplankton, whereas edible phytoplankton is more affected by zooplankton grazing (Vanni 2002). In our study, biovolumes of non-edible phytoplankton did not differ among treatments, whereas edible phytoplankton biovolumes decreased in response to $D$. longispina densities. These results suggest that phytoplankton biovolumes were strongly controlled by direct zooplankton (especially D. longispina) grazing, whereas fish effects such as remineralisation had a minor role.

\section{Trophic cascades in a warming climate}

Our results provide evidence that zooplankton taxaincluding small D. cucullata - might have a more limited influence on phytoplankton biomass in large oligotrophic lakes than the larger D. longispina. Global warming is altering pelagic food webs by shrinking animal body sizes and shifting community compositions towards a higher proportion of small-sized spe- 
cies and individuals (Daufresne et al. 2009; Geerts et al. 2015). As such, increasing temperatures that cause intraspecific or interspecific decreases in zooplankton body sizes could alter the functioning of green and brown food webs in oligotrophic freshwaters. Indeed, D. cucullata, which was rarely observed in Upper Lake Constance before 2015, became a summer-dominant cladoceran in 2017 (IGKB 2018). How recent and ongoing changes in Daphnia composition are altering ecosystem dynamics is unknown. Further research is needed to determine how body size and other functional traits interact to determine the roles of different daphniid species in trophic cascading and energy transfer from phytoplankton to fish.

\section{Conclusions}

Our study advances our understanding of species-specific roles of zooplankton in food webs and trophic cascades in oligotrophic pelagic environments. We demonstrate that considering both zooplankton and daphniids as uniform taxonomic groups, as it is common praxis, might limit understanding of links between multiple trophic levels in aquatic ecosystems. We suggest that the genus Daphnia is not a keystone taxon, but rather that large Daphnia species such as D. longispina can control food web structure at trophic levels from phytoplankton to fish. Our observation of comparable top-down predation on D. longispina by fish with specialist and generalist feeding modes suggests that the keystone role of large daphniids in oligotrophic lake food webs could extend across ecosystems with different fish predation regimes.

\section{Authors' contributions}

ŽO, CW, AJK and JIN designed the study. All authors conducted the experiment. CW analysed the data, drawings by JIN. $\breve{O}$ and $\mathrm{CW}$ prepared the manuscript with contributions from all authors. $\check{Z} \mathrm{O}$ and $\mathrm{CW}$ contributed equally to this work and share the first authorship.

\section{Acknowledgements}

We thank Claire Garfield and Alina Kindinger for their considerable help with conducting the experiment. We thank KarlOtto Rothhaupt, Dietmar Straile, Dominik Martin-Creuzburg, and Frank Peeters for useful advice about the study design. We thank Karl-Otto Rothhaupt for providing permission to install mesocosms and Dietmar Straile, Alexander Brinker and Johan Boström for statistical advice. This study was financed by the Deutsche Forschungsgemeinschaft (German Research Foundation) - 298726046/GRK2272 (RTG R3), the Bavarian State Ministry of the Environment and Consumer Protection, the Indonesian Endowment fund for education and the grant "SeeWandel: Life in Lake Constance - the past, present and future" within the framework of the Interreg V programme "Alpenrhein-Bodensee-Hochrhein (Germany/Austria/Switzerland/ Liechtenstein)", to which funds are provided by the European Regional Development Fund as well as the Swiss Confederation and cantons. The funders had no role in study design, data collection and analysis, the decision to publish, or preparation of the manuscript.

\section{References}

Adrian, R., \& Schneider-Olt, B. (1999). Top-down effects of crustacean zooplankton on pelagic microorganisms in a mesotrophic lake. Journal of Plankton Research, 21(11), 2175-2190. https://doi.org/10.1093/plankt/21.11.2175

Alexander, T. J., \& Vonlanthen, P. (2016). Artenvielfalt und Zusammensetzung der Fischpopulation im Bodensee. Kastanienbaum: Projet Lac,Eawag.

Barnett, A. J., Finlay, K., \& Beisner, B. E. (2007). Functional diversity of crustacean zooplankton communities: Towards a trait-based classification. Freshwater Biology, 52(5), 796-813. https://doi.org/10.1111/j.1365-2427.2007.01733.x

Becker, M., \& Eckmann, R. (1992). Plankton selection by pelagic european whitefish in Lake Constance: Dependency of season and time of day. Polskie Archiwum Hydrobiologii, 39, 393-402.

Bertolo, A., Lacroix, G., Lescher-Moutoué, F., \& Cardinal-Legrand, C. (2000). Plankton dynamics in planktivore-and piscivore-dominated mesocosms. Archiv für Hydrobiologie, 147(3), 327-349. https://doi.org/10.1127/archiv-hydrobiol/147/2000/327

Brett, M. T., \& Goldman, C. R. (1997). Consumer versus resource control in freshwater pelagic food webs. Science, 275(5298), 384-386. https://doi.org/10.1126/science.275.5298.384 PMID:8994034

Brooks, J. L., \& Dodson, S. I. (1965). Predation, body size, and composition of plankton. Science, 150(3692), 28-35. https:// doi.org/10.1126/science.150.3692.28 PMID:17829740

Carpenter, S. R., Kitchell, J. F., \& Hodgson, J. R. (1985). Cascading Trophic Interactions and Lake Productivity. Bioscience, 35(10), 634-639. https://doi.org/10.2307/1309989

Christoffersen, K., Riemann, B., Klysner, A., \& Sondergaard, M. (1993). Potential role of fish predation and natural populations of zooplankton in structuring a plankton community in eutrophic lake water. Limnology and Oceanography, 38(3), 561-573. https://doi.org/10.4319/lo.1993.38.3.0561

Cottee-Jones, H. E. W., \& Whittaker, R. J. (2012). The keystone species concept: A critical appraisal. Frontiers of Biogeography, 4(3), 219-224. https://doi.org/10.21425/F54312533

Cyr, H., \& Curtis, J. M. (1999). Zooplankton community size structure and taxonomic composition affects size-selective grazing in natural communities. Oecologia, 118(3), 306-315. https://doi.org/10.1007/s004420050731 PMID:28307274

Daufresne, M., Lengfellner, K., \& Sommer, U. (2009). Global warming benefits the small in aquatic ecosystems. Proceedings of the National Academy of Sciences of the United States of America, 106(31), 12788-12793. https://doi.org/10.1073/ pnas.0902080106 PMID:19620720

Eckmann, R., \& Engesser, B. (2019). Reconstructing the buildup of a pelagic stickleback (Gasterosteus aculeatus) population using hydroacoustics. Fisheries Research, 210(March), 189-192. https://doi.org/10.1016/j.fishres.2018.08.002

Eckmann, R., \& Rösch, R. (1998). Lake Constance fisheries and fish ecology. Archiv für Hydrobiologie, Special Issues. Advances in Limnology, 53, 285-301. 
Ersoy, Z., Jeppesen, E., Sgarzi, S., Arranz, I., Cañedo-Argüelles, M., . . . Brucet, S. (2017). Size-based interactions and trophic transfer efficiency are modified by fish predation and cyanobacteria blooms in Lake Mývatn, Iceland. Freshwater Biology, 62(11), 1942-1952. https://doi.org/10.1111/fwb.13039

Geerts, A.N., Vanoverbeke, J., Vanschoenwinkel, B., Van Doorslaer, W., Feuchtmayr, H., Atkinson, D., . . De Meester, L. (2015). Rapid evolution of thermal tolerance in the water flea Daphnia. Nature Climate Change, 5(7), 665-668. https://doi.org/10.1038/nclimate2628

Gianuca, A. T., Pantel, J. H., \& De Meester, L. (2016). Disentangling the effect of body size and phylogenetic distances on zooplankton top-down control of algae. Proceedings of the Royal Society B: Biological Sciences, 283(1828). https://doi. org/10.1098/rspb.2016.0487

Gliwicz, Z. M. (1990a). Why do cladocerans fail to control algal blooms? Hydrobiologia, 200-201(1), 83-97. https://doi. org/10.1007/BF02530331

Gliwicz, Z.M. (1990b). Food thresholds and body size in cladocerans. Nature, 343(6259), 638-640. https://doi. org/10.1038/343638a0

Gliwicz, Z.M. (2001). Species-specific population-density thresholds in cladocerans? Hydrobiologia, 442(1/3), 291-300. https://doi.org/10.1023/A:1017590207759

Gliwicz, Z. M., \& Pijanowska, J. (1989). The role of predation in zooplankton succession. In Z. M. Gliwicz \& J. Pijanowska (Eds.), Plankton Ecology; Succession in Plankton Communities (pp. 253-296). Berlin, Heidelberg: Springer; https://doi. org/10.1007/978-3-642-74890-5_7

Hansson, L.-A., Nicolle, A., Brodersen, J., Romare, P., Nilsson, P. A., Brönmark, C., \& Skov, C. (2007). Consequences of fish predation, migration, and juvenile ontogeny on zooplankton spring dynamics. Limnology and Oceanography, 52(2), 696-706. https://doi.org/10.4319/1o.2007.52.2.0696

Hansson, L.A., Gyllström, M., Ståhl-Delbanco, A., \& Svensson, M. (2004). Responses to fish predation and nutrients by plankton at different levels of taxonomic resolution. Freshwater Biology, 49(12), 1538-1550. https://doi.org/10.1111/ j.1365-2427.2004.01291.x

Helminen, H., \& Sarvala, J. (1997). Responses of Lake Pyhäjärvi (southwestern Finland) to variable recruitment of the major planktivorous fish, vendace (Coregonus albula). Canadian Journal of Fisheries and Aquatic Sciences, 54(1), 32-40. https://doi.org/10.1139/f96-248

IGKB (2013). Limnologischer Zustand des Bodensees, Grüner Bericht Nr. 40. https://www.igkb.org/fileadmin/user_upload/ dokumente/publikationen/gruene_berichte/40_gb40_gesamtbericht.pdf.Accessed5Oct.2020

IGKB (2018). Limnologischer Zustand des Bodensees, Grüner Bericht Nr. 42. https://www.igkb.org/fileadmin/user_upload/ dokumente/publikationen/gruene_berichte/42_gb42gesamtbericht.pdf.Accessed5Oct.2020

Iglesias, C., Jeppesen, E., Mazzeo, N., Pacheco, J. P., Mello, F. T., Landkildehus, F., . . Meerhoff, M. (2017). Fish but not macroinvertebrates promote trophic cascading effects in high density submersed plant experimental lake food webs in two contrasting climate regions. Water (Basel), 9(7), 514. https:// doi.org/10.3390/w9070514

Isanta Navarro, J., Kowarik, C., Wessels, M., Straile, D., \& Martin-Creuzburg, D. (2019). Resilience to changes in lake trophic state: Nutrient allocation into Daphnia resting eggs. Ecology and Evolution, 9(22), 12813-12825. https://doi. org/10.1002/ece3.5759 PMID:31788216
Jeppesen, E., Lauridsen, T., Mitchell, S. F., \& Burns, C. W. (1997). Do planktivorous fish structure the zooplankton communities in New Zealand lakes? New Zealand Journal of Marine and Freshwater Research, 31(2), 163-173. https:// doi.org/10.1080/00288330.1997.9516755

Jürgens, K. (1994). The impact of Daphnia on microbial food webs - a review. Marine Microbial Food Webs, 8(1-2), 295-324. Retrieved from http://hdl.handle.net/11858/00001M-0000-000F-E3AC-7

Kottelat, M., \& Freyhof, J. J. (2007). Handbook of European freshwater fishes. Cornol, Switzerland: Publications Kottelat.

Kugler, M., \& Friedl, C. (2018). Felchenfischerei, Monitoring der Blaufelchen sowie Felchen-Laichfischfang im Jahr 2017, http://www.ibkf.org/wp-content/uploads/2018/05/Blaufelchenbericht-IBKF-2018-Fangjahr-2017-final.pdf.Accessed5Oct. 2020

Kümmerlin, R., \& Bürgi, H. R. (1989). Die langjährige Entwicklung des Phytoplanktons im Bodensee (1961-986). Berichte der Internationalen Gewässerschutzkommission für den Bodensee, 39, 1-175. https://www.igkb.org/fileadmin/user_upload/dokumente/publikationen/blaue_berichte/ blauer bericht 23.pdf.Accessed5Oct.2020

Lampert, W. (1987). Feeding and nutrition in Daphnia. Memorie dell'Istituto Italiano di Idrobiologia, 45, 143-192.

Lynch, M. (1979). Predation, competition, and zooplankton community structure: An experimental study. Limnology and Oceanography, 24(2), 253-272. https://doi.org/10.4319/ 1o.1979.24.2.0253

McQueen, D. J., Johannes, M. R. S., Post, J. R., Stewart, T. J., \& Lean, D. R. S. (1989). Bottom-up and top-down impacts on freshwater pelagic community structure. Ecological Monographs, 59(3), 289-309. https://doi.org/10.2307/1942603

McQueen, D. J., \& Post, J. R. (1988). Cascading trophic interactions: Uncoupling at the zooplankton- phytoplankton link. Hydrobiologia, 159(3), 277-296. https://doi.org/10.1007/ BF00008241

McQueen, D. J., Post, J. R., \& Mills, E. L. (1986). Trophic relationships in freshwater pelagic ecosystems. Canadian Journal of Fisheries and Aquatic Sciences, 43(8), 1571-1581. https://doi.org/10.1139/f86-195

Mehner, T., Padisak, J., Kasprzak, P., Koschel, R., \& Krienitz, L. (2008). A test of food web hypotheses by exploring time series of fish, zooplankton and phytoplankton in an oligomesotrophic lake. Limnologica, 38(3-4), 179-188. https:// doi.org/10.1016/j.limno.2008.05.001

Morrow, J. E. (1980). The Freshwater Fishes of Alaska. Alaska Northwest Publishing Company.

Moyle, P. B., \& Light, T. (1996). Biological invasions of fresh water: Empirical rules and assembly theory. Biological Conservation, 78(1-2), 149-161. https://doi.org/10.1016/00063207(96)00024-9

Müller, H., Schöne, A., Pinto-Coelho, R. M., Schweizer, A., \& Weisse, T. (1991). Seasonal succession of ciliates in lake constance. Microbial Ecology, 21(1), 119-138. https://doi. org/10.1007/BF02539148 PMID:24194205

Östman, Ö., Eklöf, J., Eriksson, B. K., Olsson, J., Moksnes, P. O., \& Bergström, U. (2016). Top-down control as important as nutrient enrichment for eutrophication effects in North Atlantic coastal ecosystems. Journal of Applied Ecology, 53(4), 1138-1147. https://doi.org/10.1111/1365-2664.12654

Pagnucco, K. S., Remmal, Y., \& Ricciardi, A. (2016). An invasive benthic fish magnifies trophic cascades and alters pelagic communities in an experimental freshwater sys- 
tem. Freshwater Science, 35(2), 654-665. https://doi. org/10.1086/685285

Pauli, H. R. (1989). A new method to estimate individual dry weights of rotifers. Hydrobiologia, 186-187(1), 355-361. https://doi.org/10.1007/BF00048932

Peterka, J., \& Matěna, J. (2011). Feeding behaviour determining differential capture success of evasive prey in underyearling European perch (Perca fluviatilis L.) and roach (Rutilus rutilus (L.)). Hydrobiologia, 661(1), 113-121. https://doi. org/10.1007/s10750-010-0507-1

Peterson, W. T. (2001). Patterns in stage duration and development among marine and freshwater calanoid and cyclopoid copepods: A review of rules, physiological constraints, and evolutionary significance. Hydrobiologia, 453/454, 91-105. https://doi.org/10.1023/A:1013111832700

Post, J. R., \& McQueen, J. (1987). The impact of planktivorous fish on the structure of a plankton community. Freshwater Biology, 17(1), 79-89. https://doi.org/10.1111/j.1365-2427.1987. tb01030.x

R Core Development Team (2018). R: A language and environment for statistical computing. Vienna: R Core Development Team http://www.r-project.org

Riebesell, U., Fabry, V. J., Hansson, L., \& Gattuso, J.-P. (2011). Guide to best practices for ocean acidification research and data reporting. In U. Riebesell, K. Lee, \& J. C. Nejstgaard (Eds.), Pelagic mesocosms (pp.95-112). Luxemburg: Publications Office of the European Union. https:/www.iaea.org/ sites/default/files/18/06/oa-guide-to-best-practices.pdf

Rimet, F., \& Druart, J. C. (2018). A trait database for Phytoplankton of temperate lakes. Annales de Limnologie, 54(18), 18. https://doi.org/10.1051/limn/2018009

Des Roches, S., Shurin, J. B., Schluter, D., \& Harmon, L. J. (2013). Ecological and evolutionary effects of stickleback on community structure. PLoS One, 8(4), e59644. https://doi. org/10.1371/journal.pone.0059644 PMID:23573203

Rösch, R., Baer, J., \& Brinker, A. (2018). Impact of the invasive three-spined stickleback (Gasterosteus aculeatus) on relative abundance and growth of native pelagic whitefish (Coregonus wartmanni) in Upper Lake Constance. Hydrobiologia, 824(1), 243-254. https://doi.org/10.1007/s10750017-3479-6

Schotzko, N. (2018). Bericht zur IBKF 2018 Die Fischerei im Bodensee-Obersee im Jahr 2017. http:/www.ibkf.org/ wp-content/uploads/2018/06/IBKF_Gesamtbericht_Fangjahr2017.pdf

Schwartz, S. S. (1984). Life History Strategies in Daphnia: A Review and Predictions. Oikos, 42(1), 114-122. Retrieved from http://www.jstor.org/stable/3544616https://doi. org/10.2307/3544616

Singmann, H., Bolker, B., Westfall, J., Aust, F., \& Ben-Shachar, M. S. (2020). afex: Analysis of Factorial Experiments. R package version $0.27-2$. https://cran.r-project.org/package $=$ afex
Sommer, U., Sommer, F., Santer, B., Jamieson, C., Boersma, M., Becker, C., \& Hansen, T. (2001). Complementary impact of copepods and cladocerans on phytoplankton. Ecology Letters, 4(6), 545-550. https://doi.org/10.1046/j.14610248.2001.00263.x

Sommer, U., Sommer, F., Santer, B., Zöllner, E., Jürgens, K., Jamieson, C., .. . Gocke, K. (2003). Daphnia versus copepod impact on summer phytoplankton: Functional compensation at both trophic levels. Oecologia, 135(4), 639-647. https:// doi.org/10.1007/s00442-003-1214-7 PMID:16228259

Šorf, M., Brandl, Z., Znachor, P., \& Vašek, M. (2014). Different effects of planktonic invertebrate predators and fish on the plankton community in experimental mesocosms. Annales de Limnologie - International. Journal of Limnology, 50(1), 71-83. https://doi.org/10.1051/limn/2014001

Straile, D., \& Geller, W. (1998). Crustacean zooplankton in Lake Constance from 1920 to, 1995: Response to eutrophication and re-oligotrophication. Archiv für Hydrobiologie, Special Issues. Advances in Limnology, 53(December), 255-274. Retrieved from http://nbn-resolving.de/urn:nbn:de:bsz:352-opus-39858

Utermöhl, H. (1958). Zur Vervollkommnung der Quantitativen Phytoplankton-Methodik. Internationale Vereinigung für Theoretische und Angewandte Limnologie: Mitteilungen, 9(1), 1-38. https://doi.org/10.1080/05384680.1958.119040 91

Vakkilainen, K., Kairesalo, T., Hietala, J., Balayla, D. M., Bécares, E., Van de Bund, W. J., .. . Stephen, D. (2004). Response of zooplankton to nutrient enrichment and fish in shallow lakes: A pan-European mesocosm experiment. Freshwater Biology, 49(12), 1619-1632. https://doi.org/10.1111/j.13652427.2004.01300.x

Vanni, M. J. (2002). Nutrient cycling by animals in freshwater ecosystems. Annual Review of Ecology and Systematics, 33(1), 341-370. https://doi.org/10.1146/annurev.ecolsys.33.010802.150519

Vijverberg, J., \& Richter, A. F. (1982). Population dynamics and production of Daphnia hyalina Leydig and Daphnia cucullata Sars in Tjeukemeer. Hydrobiologia, 95(1), 235-259. https://doi.org/10.1007/BF00044487

Visser, A. W. (2007). Motility of zooplankton: Fitness, foraging and predation. Journal of Plankton Research, 29(5), 447-461. https://doi.org/10.1093/plankt/fbm029

Williams, A. E., \& Moss, B. (2003). Effects of different fish species and biomass on plankton interactions in a shallow lake. Hydrobiologia, 491(1-3), 331-346. https://doi. org/10.1023/A:1024456803994

Zöllner, E., Santer, B., Boersma, M., Hoppe, H.-G., \& Jürgens, K. (2003). Cascading predation effects of Daphnia and copepods on microbial food web components. Freshwater Biology, 48(12), 2174-2193. https://doi.org/10.1046/j.13652426.2003.01158.x

Manuscript received: 20 June 2020

Revisions requested: 12 September 2020

Revised version received: 12 October 2020

Manuscript accepted: 12 October 2020 